\title{
Modeling of Functional Interactions
}

National Cancer Institute

\section{Source}

National Cancer Institute. Modeling of Functional Interactions. NCI Thesaurus. Code C18880.

Using mathematical methods to simulate processes to predict the interaction of proteins at the functional level. 